Journal of Balkumari College

ISSN 2467-9321 (Print), ISSN 2738 -957X (Online) Website: http://balkumaricollege.edu.np/journal

Volume : 10 Issue: 1 June 2021, Page No. 94-100

\title{
Nutritional Status And Its Impact On The Occurance Of Complications In Children With Acute Lymbhoblastic Leukemia During 1Stinduction Chemotherapy: The Experience At Bp Koirala Memorial Cancer Hospital.
}

\author{
Sushila Koirala, \\ Sr. Nursing Officer, Faculty Member, BPKMCH Nursing College \\ koiralasilu@gmail.com
}

\begin{abstract}
Malnutrition is a common problem in cancer patients. It has been recognized as an important component to influence on tolerance to treatment, increased morbidity, poor prognosis, decreased quality of life and increased health care costs. Acute leukemia is the most common malignancy in children of which acute lymphoblastic leukemia accounts for majority of the cases $(75 \%)$. Chemotherapy is the main treatment modality for acute lymphoblastic leukemia(ALL). Under nutrition can contribute to the incidence and severity of treatment side effects and increases the risk of infection, thereby reducing the chances of survival.
\end{abstract}

Objectives: To evaluate pretreatment nutritional status (BMI) in children with ALL and its effects during first induction chemotherapy.

Methodology: This observational study included sixty-two consecutive children with acute lymphoblastic leukemia, admitted in Haemato-Oncology Ward of BPKMCH over a period of 27 months $\left(15^{\text {thy }}\right.$ May, 2015 to $15^{\text {th }}$ July, 2017) were measured for height and weight to calculate BMI for assessing nutritional status at presentation. Children were grouped into 2 group: normal weight and underweight usingCDC BMI percentile chart by World Health Organization(WHO). Day to day observation and documentation were maintained to identify any side effects and complications over a period of first induction chemotherapy.

Findings of the study: Among 62 cases, majority were male $(66 \%)$. Three forth of the cases were B-cell ALL. More than 34 percent of the cases (27) had under- weight $\left(\mathrm{BMI}<5^{\text {th }}\right.$ percentile). Effects like very severe neutropenia, febrile neutropenia, infections, musculoskeletal problems, severe pancytopenia, G/I problems were noted mostly in children with underweight.

Conclusion: Baseline nutritional status negatively influences in the occurrence of complications during induction chemotherapy in children with ALL. The nutritional support has to be personalized according to the nutritional status of the single patient.

Key words: Malnutrition, Acute Lymphoblastic Leukemia, Induction Chemotherapy, Problems

\section{Introduction}

Malnutrition is a global problem which is most prevalent in underdeveloped and middle level countries especially in southern Asia. Malnutrition is still very much prevalent in Nepal, mainly among young children, adolescents and newly mothers.Overall,36\% of children under age 5 are stunted, $10 \%$ are wasted, and $27 \%$ are underweight in Nepal ((Ministry of Health (MOH) et al. 2017).

Malnutrition is a common problem in pediatric cancer patients. Malnutrition has been associated with decreased tolerance to chemotherapy, possibly increased infection rates, and overall reduced well -being and quality of life (Iniesta, Paciarotti, Brougham, McKenzie, \& Wilson, 2015).

Nutrition influences most cancer control parameters in pediatric oncology, including prevention, epidemiology, biology, treatment, supportive care, recuperation, and survival (Rogers, 2015). It is widely recognized that the nutritional status of children diagnosed with and treated for cancer will be probably affected during the course of the disease. 
Children more commonly present with malnutrition at diagnosis of cancer in developing countries than in developed countries, depending on the type of cancer and extent of the disease. Malnutrition at cancer diagnosis is associated with delays in treatment, increased infections and a negative outcome.

The presence of undernutrition correlates with a greater number of complications and relapses, as well as with decreased level of recovery (Sala et al, 2004). Poor nutritional state is a clear prognostic factor for treatment response and has an effect on the outcome of children with cancer (Gaynor\& Sullivan, 2015).

Acute leukemia is the most common malignancy in children of which acute lymphoblastic leukemia accounts for majority of the cases $(75 \%)$. Chemotherapy is the main treatment modality for acute lymphoblastic leukemia (ALL). Under nutrition can contribute to the incidence and severity of treatment side effects and increases the risk of infection, thereby reducing the chances of survival (Vigano, Watanabe, \& Bruera, 1994)

Acute Lymphoblastic Leukemia (ALL) is the most frequently occurring cancer among the children and adolescents. Cure rate is improved up to $90 \%$ with early diagnosis and better supportive care. Under nutrition among pediatric acute leukemia patients is more in developing countries $60 \%$ as compared to $10 \%$ in developed countries. The poor nutritional status is found to be associated with poor outcome. Therefore, optimum nutritional support can play a vital role in the outcome of induction(Khalid,2017).

Malnutrition is prevalent on large scale in hospitalized patients especially in developing and under developed countries, who increases morbidity and mortality, reduces the effectiveness of medical treatment, and impairs the quality of life significantly. Early diagnosis and management of malnutrition is very important while treating the leukemic children.

So, this study was conducted to assess the influence of undernutrition in children with ALL during induction chemotherapy and to observe its effect on tolerance to subsequent chemotherapy in terms of the incidence and severity of complications.

\section{Methodology}

This observational study included sixty-two consecutive children with newly diagnosed acute lymphoblastic leukemia (ALL) presenting to the pediatric hematology-oncology ward of B.P Koirala Memorial Cancer Hospital, Chitwan, Nepal. This study was conducted over a period of 27 months (1 $5^{\text {thy }}$ May, 2015 to $15^{\text {th }}$ July, 2017).

Children were measured for height and weight to calculate BMI for assessing nutritional status at presentation. Day to day observation and documentation were maintained to identify any side effects and complications over a period of first induction chemotherapy. Children were grouped into 2 group: normal weight and underweight using CDC BMI percentile chart by World Health Organization (WHO). Children below 2 years of age and children who started induction chemotherapy in other hospital before admitting in BPKMCH and relapsed cases were excluded in this study. There were only 4 children with over -weight so they were also excluded.

Induction chemotherapy for children with ALL included (protocol 841) 4 weeks of daily prednisolone, weekly vincristine ( 5 doses), Intrathecal methotrexate ( 5 doses) and 10 doses of $\mathrm{L}-\mathrm{Asparagines.} \mathrm{Neutropenia} \mathrm{was} \mathrm{defined}$ as absolute neutrophil count (ANC) $<1000 / \mathrm{mm}^{3}$ (mild neutropenia- ANC 500-1000, Moderate ANC 100- 500 and for Severe neutropenia ANC $<100$ ). Pancytopenia was defined as hemoglobin $<9 \mathrm{gm} / \mathrm{dl}, \mathrm{ANC}, 1000 / \mathrm{mm}^{3}$ and platelets count $<50000 / \mathrm{mm}^{3}$. Febrile neutropenia was defined as temperature more than $100.5^{\circ}$ fand ANC $<500 /$ $\mathrm{mm}^{3}$. Gastro- intestinal (G/I) problems was defined as having problems any two or more of these symptoms: nausea, vomiting, diarrhea, constipation and abdominal pain and likewise musculo-skeletal (M/S) problems was defined as problems of myalgia, bone pain, and fatigue.

Statistical Package for Social Sciences (SPSS) software version 16 was used to analyze the data.

descriptive statistics was used to measure frequency of problems occurred during induction chemotherapy and $p$ value was calculated to assess the statistically significant between nutritional status and different problems during induction chemotherapy. 


\section{Finding And Interpretation}

Table 1: Types of leukemia

\begin{tabular}{|l|l|}
\multicolumn{1}{|c|}{ Type of Leukemia } & \multicolumn{1}{c|}{ No. (\%) } \\
\hline B-Cell & $46(74.2)$ \\
\hline T- Cell & $16(25.8)$ \\
\hline Total & $62(100)$ \\
\hline
\end{tabular}

Table 1 shows that out of 66 ALL cases, majority of them nearly three forth(74.2 percent) were B -Cell ALL and one fourth cases constitute T -Cell ALL.

Table 2: Sex and Weight

\begin{tabular}{|l|l|l|l|}
\multicolumn{1}{c}{ Sex } & \multicolumn{1}{c}{$\begin{array}{c}\text { Normal weight } \\
\text { No. (\%) }\end{array}$} & \multicolumn{1}{c|}{$\begin{array}{c}\text { Under weight } \\
\text { No. (\%) }\end{array}$} \\
\hline Male & $21(51.2)$ & $20(48.8)$ & $41(66.1)$ \\
\hline Female & $14(66.7)$ & $7(33.3)$ & $21(33.9)$ \\
\hline Total & $35(56.5)$ & $27(43.5)$ & $62(100)$ \\
\hline
\end{tabular}

Table 2 shows that majority of the cases were male (66.1 percent). Among them nearly half of them are underweight. Female constitutes 33.9 percent of cases where 43.5 percent are underweight.

Table-3: Age and Weight

\begin{tabular}{|c|c|c|c|}
\hline \multirow{2}{*}{ Age (in year) } & $\begin{array}{c}\text { Normal weight } \\
\text { No. (\%) }\end{array}$ & $\begin{array}{c}\text { Under weight } \\
\text { No. (\%) }\end{array}$ & Total (\%) \\
\hline $2-5$ & $15(68.2)$ & $13(56.5)$ & $28(45.2)$ \\
\hline $6-10$ & $10(58.8)$ & $7(41.2)$ & $17(27.4)$ \\
\hline $10+$ & $10(43.5)$ & $7(31.8)$ & $17(27.4)$ \\
\hline Total & 35 & 27 & $62(100.0)$ \\
\hline
\end{tabular}

Table 3 reveals that majority of the cases 45.2 percent belongs to age group of $2-5$ years and majority of underweight children are also from this age group. Children with $6-10$ years and 10 plus years have equal percent that means they constitute same number (17 out of 62).

\section{Table 4: Pancytopenia and body weight}

\begin{tabular}{|l|c|c|c|}
\multicolumn{1}{c}{ Weight } & \multicolumn{2}{c}{ Pancytopenia } & \multicolumn{1}{c|}{$\begin{array}{c}\text { Total P-value } \\
<\mathbf{0 . 0 0 1 *}\end{array}$} \\
& $\begin{array}{c}\text { Yes } \\
\text { No. (\%) }\end{array}$ & $\begin{array}{c}\text { No } \\
\text { No. (\%) }\end{array}$ & 35 \\
\hline Normal weight & $4(11.4)$ & $31(88.6)$ & 27 \\
\hline Under weight & $16(59.3)$ & $11(40.7)$ & 62 \\
\hline Total & $20(32.3)$ & $42(67.7)$ & \\
\hline
\end{tabular}

\section{Statistically significant $* P<0.001$}

Table 4 reveals that among 62 children, 20 (32.3\%) have pancytopenia. This table also shows that only 11.4 percent of normal weight cases developed pancytopenia and nearly 60 percent of underweight cases have pancytopenia. 
Table 5: Electrolyte Imbalance and Body Weight

\begin{tabular}{|c|c|c|c|}
\hline & \multicolumn{2}{|c|}{ E Electrolyte Imbalance } & \multirow[b]{2}{*}{ Total } \\
\hline & $\begin{array}{c}\text { Yes } \\
\text { No. }(\%)\end{array}$ & $\begin{array}{l}\text { No } \\
\text { No. }(\%)\end{array}$ & \\
\hline Normal Weight & $0(0)$ & $35(100)$ & 35 \\
\hline Under Weight & $7(25.9)$ & $20(74.9)$ & 27 \\
\hline Total & $7(11.3)$ & $55(88.7)$ & 62 \\
\hline
\end{tabular}

Table 5 reveals that 11.3 percent children with ALL have electrolyte imbalance. Normal weight cases have not resulted electrolytes imbalance where as 25.9 percent of underweight children have electrolytes imbalance.

Table 6: Neutropenia and Body Weight

\begin{tabular}{|c|c|c|c|c|}
\hline \multicolumn{5}{|c|}{ Neutropenia } \\
\hline & $\begin{array}{c}\text { Mild No. } \\
(\%)\end{array}$ & $\begin{array}{c}\text { Moderate } \\
\text { No. }(\%)\end{array}$ & $\begin{array}{l}\text { Severe } \\
\text { No. }(\%)\end{array}$ & Total P - Value $<0.001 *$ \\
\hline Normal Weight & $14(40.0))$ & $17(48.6)$ & $4(11.4)$ & 35 \\
\hline Under Weight & $2(7.4)$ & $4(14.8)$ & $21(77.8)$ & 27 \\
\hline Total & $16(25.8)$ & 21(33.9) & $25(40.3)$ & $62(100)$ \\
\hline
\end{tabular}

Statistically significant $*<0.001$

Table 6 shows that all children have developed neutropenia. Most of the children with normal weight have mild to moderate neutropenia 40 percent and 48.6 percent respectively whereas most of the children with underweight have moderate to severe neutropenia (33.9 percent and 40.3 percent). Underweight is strongly significant with severe neutropenia.

Table 7: Infection and Body Weight

\begin{tabular}{|c|c|c|c|c|}
\hline & \multicolumn{2}{|c|}{ Infection } & & \multirow[t]{2}{*}{ P- value } \\
\hline & $\begin{array}{c}\text { Yes } \\
\text { No. }(\%)\end{array}$ & $\begin{array}{c}\text { No } \\
\text { No. }(\%)\end{array}$ & Total & \\
\hline Normal Weight & $0(0)$ & $35(100)$ & 35 & $<0.001^{*}$ \\
\hline Under Weight & $10(37)$ & $17(63)$ & 27 & \\
\hline Total & $10(16.1)$ & $52(83.9)$ & 62 & \\
\hline
\end{tabular}

\section{Statistically significant $* \boldsymbol{P}<0.001$}

Table 7 shows that cases with normal weight have no signs of infection but 37 percent of underweight cases developed infection during $1^{\text {st }}$ induction phase. This table also reveals that under weight is strongly associated with infection.

Table 8: Febrile Neutropenia and Body Weight

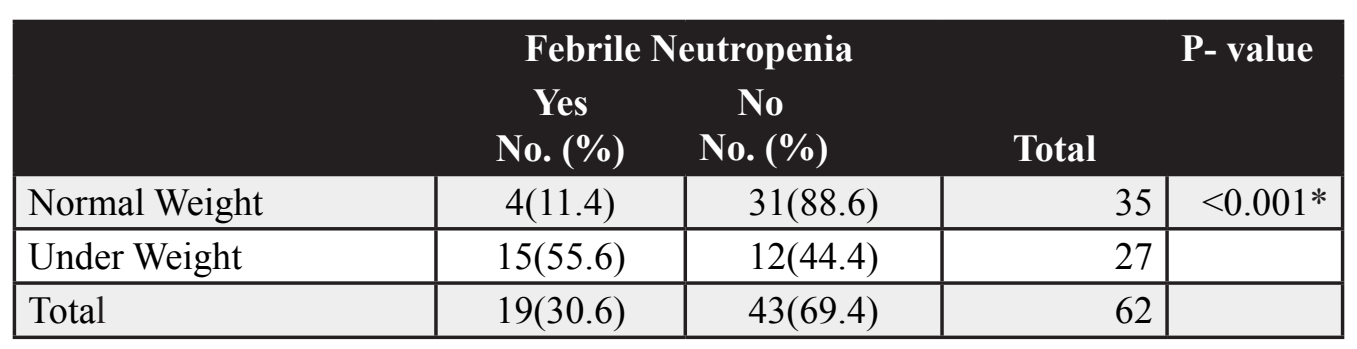

Statistically significant * $\boldsymbol{P}<\mathbf{0 . 0 0 1}$

Table 8 shows that out of 35 normal weight children, only 11.4 percent of them developed febrile neutropenia and out of 27 underweight children 15(55.6 percent) developed febrile neutropenia. This table also reveals that febrile neutropenia is significantly associated with underweight. 
Table 9: G/I Problems and Body Weight

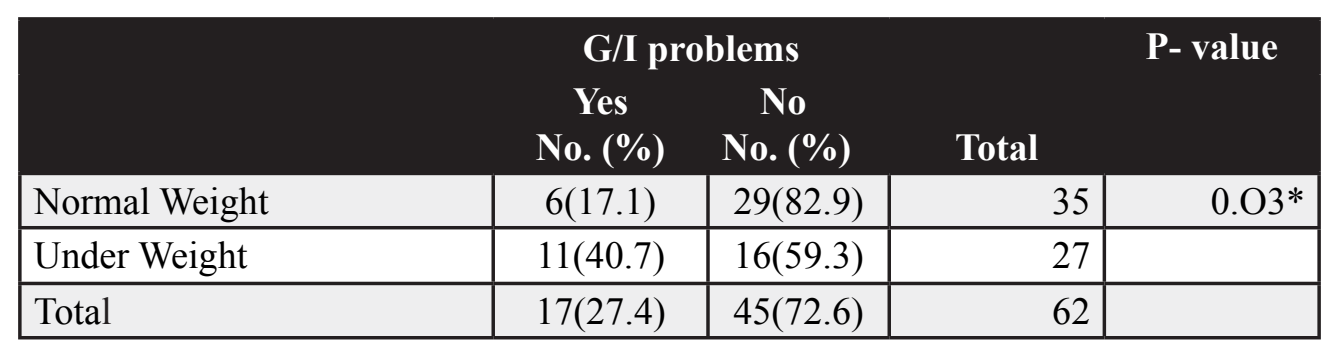

\section{Statistically significant $* \boldsymbol{P}<0.05$}

Table 9 shows that nearly 27 percent children with ALL have G/I problems. Among normal weight children only 17 percent have G/I problems whereas 59.3 percent of underweight cases have developed G/I problems.

Table 10: Musculo- Skeletal Problems and Body Weight

\begin{tabular}{|l|c|c|r|r|}
\multicolumn{5}{|c|}{ M/S problem } \\
\multicolumn{1}{|c|}{ Yes } & \multicolumn{1}{c|}{ No } & Total & \multicolumn{1}{c|}{ P value } \\
\hline Normal Weight & $6(17.1)$ & $29(82.9)$ & 35 & $<0.001$ \\
\hline Under Weight & $16(59.3)$ & $11(40.7)$ & 27 & \\
\hline Total & $22(35.5)$ & $40(64.5)$ & 62 & \\
\hline
\end{tabular}

\section{Statistically significant $* \mathbf{P}<\mathbf{0 . 0 0 1}$}

Table 10 reveals that 35.5 percent of study children have musculo-skeletal problems. Among normal weight children, only 17 percent of normal weight children have musculo-skeletal problems and nearly 60 percent of children with underweight have musculo- skeletal problems. This table also shows that there is strong association of under-weight children and musculo-skeletal problems.

Table 11: Body weight and Bone Marrow Status (Remission -bone marrow blast $<5 \%$ )

\begin{tabular}{|l|l|l|l|}
\multicolumn{1}{c}{} & \multicolumn{1}{c}{ Yes } & No & \multicolumn{1}{c|}{ Total } \\
\multicolumn{1}{c|}{ No. (\%) } & No. (\%) & \multicolumn{1}{c|}{} \\
\hline Normal Weight & $30(85.71)$ & $5(14.28)$ & 35 \\
\hline Under Weight & $11(40.70)$ & $16(59.29)$ & 27 \\
\hline Total & $41(66.13)$ & $21(33.87)$ & 62 \\
\hline
\end{tabular}

Table 11 presents that among 62 children, there are $4166.13 \%$ ) children who have got remission on day 14 of induction during bone marrow examination and 21(33.87\%) children have poor bone marrow status. More than 58 percent of normal weight children have got remission whereas only 40.70 percent of underweight children have remission on day 14 .

Table 12: Body Weight and Bone Marrow Status at day 28 of Induction (Remission- blast $<5 \%$ )

\begin{tabular}{|c|c|c|c|}
\hline & \multicolumn{2}{|c|}{ Remission } & \multirow[b]{2}{*}{ Total } \\
\hline & $\begin{array}{c}\text { Yes } \\
\text { No. }(\%)\end{array}$ & $\begin{array}{c}\text { No } \\
\text { No. }(\%)\end{array}$ & \\
\hline Normal Weight & $35(100 \%)$ & $0(0 \%)$ & 35 \\
\hline Under Weight & $22(81.48)$ & $5(18.52)$ & 27 \\
\hline Total & $57(91.93)$ & $5(8.07)$ & 62 \\
\hline
\end{tabular}

Tables 12 reveals that more than 91 percent of children with ALL have remission during bone marrow examination on day 28 of induction chemotherapy where cent percent of normal weight children have remission but nearly 19 percent of underweight children have poor bone marrow recovery status. 


\section{Discussion}

The purpose of this study was to evaluate the impact of nutritional status during induction phase in children with acute lymphoblastic leukemia. BMI was calculated for grouping the child as under -weight and normal weight to assess their nutritional status. Day to day observation and review of nurses' records were made to assess any effects and complications during induction chemotherapy.

Nutrition is a basic part of the pediatric cancer patients. it is clear that adequate and appropriate nutrition in necessary to maintain their optimal growth and development. furthermore, adequate nutrition is likely to increase treatment response, reduce toxicity of chemotherapy and improve quality of life.

Among 62 children, 41 were male and 21 were female. Nearly $44 \%$ children were under -weight and most of them 46(74.2\%) were children with B- cell acute lymphoblastic Leukemia. Regarding the age group, more than 45 percent children were from 2 to $5 \mathrm{yrs}$. This data is matched with the global schenario of leukemia in children. This study also found out that among 62 study children, pancytopenia(32\%), febrile neutropenia31\%,infections(16\%), G/I problems $(27.4 \%)$,electrolyte imbalance(11\%) and musculo- skeletal problems( 36\%) were noted. $66 \%$ children were in remission at day 14 and $91 \%$ in remission on day 28 day of induction chemotherapy.There was strong association of underweight with severe neutropenia( $P<0.001)$, pancytopenia $(P<0.001)$, episodes of febrile neutropenia $((P<0.001)$, infections $(P<0.001)$, gastro-intestinal problems $(p<.03)$, musculo- skeletal problems $(p<0.001)$, bone marrow recovery status was poor in nearly 60 percent and 8 pertcent of underweight children on day 14 and day 28 respectively. This study found out that most of the complications and side effect of treatment are resulted in undernutrient children. Children with good nutritional status at diagnosis have better treatment response.

\section{Conclusion}

Poor nutritional status negatively influences in the occurrence of complications during induction chemotherapy in children with ALL. Nutritional assessment should be done from diagnosis during treatment and subsequently for the early diagnosis and management of this important prognostic factor that has crucial role in treatment response and the possibility of recovery. to manage and control possible complications and adverse effects thereby improving the nutritional support has to be personalized according to the nutritional status of the single child with leukemia. There is very need of specific dietary guidelines for children with cancer. Early monitoring of nutritional status in leukemic children and timely nutritional intervention can improve the treatment response, their clinical outcome.

\section{REFERENCES}

Antillon, F., de Maselli, T., Garcia, T., Rossi, E., \& Sala, A (2008). Nutritional Status of Children during Treatment for Acute Lymphoblastic Leukemia in the Central American Pediatric Hematology Oncology Association (AHOPCA): Preliminary Data from Guatemala. Pediatric Blood and Cancer, 50, 502-505. doi: 10.1002/ pbc. 21398

Antillon, F., Rossi, E., Molina, A.L., Sala, A., Pencharz, P., Valsecchi, M.G., \& Barr, R (2013). Nutritional Status of Children during Treatment for Acute Lymphoblastic Leukemia in Guatemala. Pediatric Blood Cancer,60, 911-915. doi: 10.1002/pbc.24377.

Barr, R.D. (2015). Nutritional Status in Children with Cancer: Before, during and after Therapy. Indian Journal of Cancer, 52, 173. doi: 10.4103/0019-509X.175827.

Barr, R.D., Atkinson, S., Pencharz, P., \& Arguelles, G.R. Nutrition and Cancer in Children (2008).PediatricBlood Cancer, 50, 437. Retrieved from https://doi.org/10.1002/pbc.21418 on July 17.

Barr, R.D. Gomez-Almaguer, D. Jaime-Perez, J.C. Ruiz-Argüelles, G.J. Importance of Nutrition in the Treatment of Leukemia in Children and Adolescents. Archive of Medical Research, 2016, 47(8), 585-592.

Brinksma, A., Huizinga, G., Sulkers, E, Kamps, W., Roodbol. P. \& Tissing, W. (2012). Malnutrition in Childhood Cancer Patients: A Review on Its Prevalence and Possible Causes. Critical Review. Oncology/ Hematology., 83, 249-275. Retrieved from https:/www.sciencedirect.com/science/article/abs/pii/ S1040842811002770?via\%3Dihubon Jun1. 
Bauer, J., Jürgens, H., \& Frühwald, M.C (2011). Important Aspects of Nutrition in Children with Cancer. Advances in Nutrition. 2, 67-77. doi:10.3945/an.110.000141.

CDC Growth Charts. Retrieved online fromhttp://www.cdc.gov/growthcharts on 13th Jan, 2014.

Dos Maia Lemos, P.S., Ceragioli Oliveira, F.L., Monteiro-Caran, E.M (2016). Nutritional Status at Diagnosis in Children with Cancer in Brazil. Pediatrics and Therapeutics, 6(3). doi 10.4172/2161-0665.1000295.

Gaynor, E.P.T, \& Sullivan, P.B (2015). Nutritional Status and Nutritional Management in Children with Cancer. 100, 1169-1172. doi:10.1136/archdischild-2014-306941

Iniesta, R.R., Paciarotti, I., Brougham M.F., McKenzie J.M. \& Wilson D.C. (2015). Effects of pediatric cancer and its treatment on nutritional status: A systematic review. 73, 276-295. doi: 10.1093/nutria/nuu062.

Jaime-Pérez, J.C., González-llano, O., Herrera-Garza, J.L., Gutiérrez-Aguirre, H., Vázquez-Garza, \& E., GómezAlmaguer, D. Assessment of Nutritional Status in Children with Acute Lymphoblastic Leukemia in Northern México: A 5-Year Experience. Pediatric Blood and Cancer, 2008, 50, 506-508.

Loeffen, E.A.H., Brinksma, A., Miedema, K.G.E., de Bock, G.H., \& Tissing, W.J.E. (2015). Clinical Implications of Malnutrition in Childhood Cancer Patients - Infections and Mortality. Support. Care Cancer, 23, 143150 .

Ministry of Health (MOH), New ERA, and ICF (2017). Nepal Demographic and Health Survey 2016. Kathmandu, Nepal: Author.

Radhakrishnan, V., Ganesan, P. (2015). Rajendranath, R., Ganesan, T.S., Sagar, T.G. (2015). Nutritional Profile of Pediatric Cancer Patients at Cancer Institute, Chennai. Indian Journal of Cancer, 52, 207-209. doi:10.4103/0019-509X.175841.

Rogers, PC. (2014). Nutritional status as a prognostic indicator for pediatric malignancies. Journal of clinical oncology. 32, 1293-1294.

Rogers, P.C (2015). Importance of Nutrition in Pediatric Oncology (2015). Indian Journal of. Cancer. 52, 176178.

Sala, A., Pencharz, P., \&Barr, R.D (2004). Children, Cancer, and Nutrition-A Dynamic Triangle in Review. 100, 677-687.

Sala, A., Rossi, E., Antillon, F., Molina, A.L., de Maselli, T., Bonilla, M.; Hernandez, A., Ortiz, R, Pacheco, C., Nieves, R.,...Barr, A (2012). Nutritional Status at Diagnosis Is Related to Clinical Outcomes in Children and Adolescents with Cancer: A Perspective from Central America. European Journal of Cancer, 48(2), $243-252$.

UNICEF (2017). The State of the World's Children. Retrieved from https://www.unicef.org/reports/state-worldschildren-2017 on Dec .2017. 